\title{
Exploring embodied methodologies for transformative practice in early childhood and youth
}

\author{
Helen Cahill, Julia Coffey, Kylie Smith
}

\begin{abstract}
The development of gendered identities during early childhood and youth occurs in a context of 'body culture' and the hyper-visibility of 'perfect' bodies, which align with traditional gender ideals. Embodied methods can assist to make complexity more visible, and to allow participants to see fluidity, shifts, and becoming. Whilst there has been significant theoretical development, further methodological innovations are needed to enable children and youth to articulate their perceptions of the way multiple influences shape their relations with their own bodies. Informed by 'new materialist' feminist theory this article will examine the work of Australian educators exploring use of creative and embodied drama-based play. The chapter advances methodologies to support pedagogical engagement with young children and youth about gender, identity and social change. The authors explore how embodied creative play can be used across ages to support children and young people to articulate the ways social norms and expectations influence their desires, imaginings, fears and actions and their perceptions of what is possible, desirable or appropriate in relation to performances of gender in their everyday worlds.
\end{abstract}

Key words: new materialism, embodiment, post-humanism, feminism, gender.

\section{New Materialist Theory and Methodologies}

Feminist new materialist perspectives have recently been taken up in educational research. These approaches direct attention to the way in which 'material things act on and with us' to produce human practices (Taylor $\&$ 
Ivinson, 2013, p. 689). This theoretical perspective encourages recognition of the interaction between the human and the non-human, incorporating the relationships between forces, events, material objects and humans, insisting on the 'meaning, force, and value of materiality' (Alaimo \& Hekman, 2008, p. 10). For researchers, this means engaging with the 'fullness of materiality', including the bodies of our research subjects, and the way in which the material world as well as discourses work to shape them. This perspective, also termed 'a feminist material diffractive approach', drawn from the work of Barad, Braidotti and other feminist post-human theorists, encourages new ways of looking at research practice (Taylor \& Ivinson, 2013, p. 691).

At the simplest level, a materialist perspective encourages attention to embodiment and the material body (Alaimo \& Hekman, 2008). This focus is being taken up to explore the material ways in which bodies matter in research and in learning. The question of how to better em-body theory and research has been central in recent developments in feminist materialist perspectives (Coleman, 2013). Feminist new materialism is drawn largely from Barad's (2007) theories of agential realism on the intra-active constitution of matter; as well as Braidotti's (2013) theories of post-humanism. These perspectives revalue the importance of matter in human practices (Edwards \& Fenwick, 2014).

Agential realism is the strategy or theory by which Barad understands matter as an inherently dynamic and shifting entanglement of relations (2007, p. 35). Through this framework, Barad reconceptualises agency, causality, and materiality. In contrast to 'interaction', which is founded on the premise that there are separate entities that precede their interaction, Barad uses the term 'intra-action' to theorise that entities, or 'agencies', do not exist prior to their interaction, but that rather both are constituted through their meeting $(2007$, p. 33). This perspective reconceptualises matter and discourse; neither pre-exists the other, leading to a dynamic and indeterminate conceptualisation of agency.

Barad's theory emphasises the interconnectedness of all things. Rather than there being a neat separation between human bodies and objects and environment, these things all interconnect and influence each other. For example, using this type of thinking it could be seen that in schools, the desk shapes the student, and her ideas about what it means to be a learner, just as she, the student, endorses the function of desk by working (or not) upon it. The desk governs the body and enacts the presumption that the mind is the site of learning. The very practice of sitting students in desks to 
learn enacts the presumption that learning occurs through the mind, held to be separate from the body. Bodies should then be controlled and stilled to facilitate learning through the mind. Using this theory, it can be seen that people are always in a state of flux as they engage with, are affected by, and in turn affect all elements of their environments.

Renold and Ringrose (2014), among many others, have drawn on Barad's concepts of diffraction and intra-action to foreground the entanglements which comprise research assemblages. To undertake a 'diffractive reading' entails a 'respectful, detailed, ethical engagement' with 'data' and all aspects of the research assemblage (see Hickey-Moody, 2015, p. 808). It is a way of foregrounding the researcher in the research assemblage, and acknowledging the researcher's role in terms of 'an ethico-political commitment where the production of knowledge is about making a difference in the world and understanding the what, where, when, how, and for whom differences matter (Barad, 2007)' (Ringrose \& Renold, 2014, pp. 1-2).

This perspective also raises important questions about the kinds of 'knowledge' that research can produce (Fox \& Alldred, 2014). It is one thing to theorise about the fluid interconnectedness of everything, however keeping everything in mind at once is too tall an order in research. The investigator must inevitably segment off some things for attention, whilst allowing other aspects of experience to slip into invisibility. That these unattended matters are not accounted for in the research however, does not mean that they don't matter, or that they have no effect. Rather, in response to materialist theory, researchers understand the need to pay more explicit attention to the way in which their frame of reference influences what can be seen in research, and the way in which their questions and the mediums through which they ask them also have this framing effect for their research subjects. Typically some aspects of experience are left unaccounted for, simply because they are taken for granted within everyday practice. It is more common for example to ask how does the teacher, the task or the test affect learning, than to inquire into the effect of the furniture upon the pedagogical imagination.

In this article, we consider examples of pedagogical innovation occurring in early childhood and high school settings, each of which seek to 'enable' respondents to account for some aspects of the embodied nature of their experiences- and to account for the way in the very objects and approaches used in research have a function in shaping the way in which respondents articulate or enact their knowledge. In doing this we take a materialist per- 
spective on the way in which things as well as persons work to shape options and possibilities in relation to gender.

\section{Using Diversity Dolls in Early Childhood Encounters}

Our first example is drawn from the third author's research into constructions of gender in early childhood (Smith, 2013). Observation is the dominant tradition of research in early childhood settings, with investigators taking an interest in the way children's behavior gives clues about cognitive or social development. While there is a body of work where researchers explore children's understandings of gendered identities through discussions or interviews with children (see Davies, 2003), it is much less common for investigators to themselves attempt to engage dialogically with the thinking of young children in relation to identity development. Use of the Persona Doll (Smith, 2013) as method has emerged as a method in which the investigator can engage dialogically, operating within the bounds of fantasy play - thus researching inside the interactions with the children, rather than remaining as the separate 'helicopter' observer.

Typically, the Persona Doll is brought in to meet the class, presenting as 'someone' who has a problem, requiring the assistance of the children (Smith, 2013). The facilitator shares the doll's story, introducing the predicament. The doll presents with a story line, as well as an obvious embodied presence through which both gender and race are represented. Thus the 'presenting problem' around which the embodied and voiced dialogue will emerge is introduced through a material embodied presence via the life-size doll, a 'human' who is not quite fully human, and thus needs assistance from the surrounding others.

The moments to be explored in research commonly revolve around things like unfairness or loss or choice. Hence the predicaments are of a highly social nature, encapsulating ethical and relational choices.

One example of using the dolls to support an encounter around gender in the early childhood classroom was when Lilly, a Vietnamese girl doll was introduced to a group of three and four year old Australian children (Smith, 2013). Lilly's predicament was contained in her account of the day she had attended her early childhood classroom wearing her favorite jeans, only to be told by her peers that she couldn't play with the other girls because she wasn't wearing a dress or skirt as they were. The children were asked to talk about what they thought Lilly should do about being excluded from 
play by her peers (Smith, Alexander \& D'Souza Juma, 2014). The girls in the class sat up straight and looked at each other with authority, signalling through the embodied actions of flicking their hair and patting and adjusting their skirts and dresses that they would argue that Lilly should wear a dress the next day. The girls looked to and from each other and nodded to each other in agreement whilst variously adjusting necklaces and headbands. One of the children gestured with her hand at Lilly's jeans saying "she just needs to wear a dress!" As the girls performed their girlhood expertise through bodies and dialogue so too did the boys. However they remained silent throughout the whole conversation. Two of the boys laid back on the ground, reaching behind them to get a car to play with, signaling through their bodies that they disengaged from a feminized encounter and reconnected with a boyhood territory through their selection of objects. Once the storytelling session was completed, the Lilly doll was left in the room for the children to interact with. Some of the girls moved her into their play space, constructing a 'home' area where the girls traded shoes, fluffy jackets and head bands with each other and used material to create skirts and wraps. During this play the doll was welcomed in to the space without having to wear a dress or skirt. In contrast with what had been said and signaled in the prior activity, during free play Lilly was carried into spaces and more inclusive story encounters were embodied and enacted within and through the doll. Affrica Taylor (2013) drawing on Latour $(2004,2005)$ writes:

In other words, children's common worlds are impure and emerging worlds, produced through ongoing heterogeneous relations that take place within and between a whole host of actors (living beings) and actants (things and non-living forces). (p. 80)

Use of observer method commonly used in early childhood settings does not readily permit the complexity of children's thinking to be revealed. An observer of the free play may have deduced that the children had little interest in policing gender rules around dress. However, engagement through the narrative and associated 'body languaging' about the predicament of the doll revealed that the children knew and could strategically police gender rules. This data, read in association with the behaviours within the free play revealed also that the girls could also at times bargain with the gender rules, make exceptions and bend or break them when they wish to reap benefits which these rules preclude. The intra-actions between the bodies of the children and the non-human-but-humanised Lilly through doll-play role-play helped them to reveal the various ways they made sense of the world and 
how they navigated what was possible or desirable when acting in what they imagine the world beyond them to be.

\section{Using Drama as the Distorting Mirror}

A similar insight into the challenge of eliciting complex responses in research can be seen when examining what can be made possible through use of embodied drama methods. Theatre is a medium which presumes that communication will occur through the body. Both embodied and spoken texts are 'read' by the audience - and experiences are understood to be three-dimensional - occurring as interactions between people, places, things and the passage of time. In the following examples, surrealist dramabased play is used as the pedagogical strategy through which to investigate thinking about social relations on matters to do with gender and sexuality. These examples point to a tension between the knowledge created via naturalistic role-play, which thrives upon the re-articulation of dominant stories, with their types and tropes, and that elicited within surrealist dramatic play, which encourages a more diffractive engagement with reading 'reality' and more readily permits the construction of alternative theories and meanings.

\section{Capturing the discourse at play}

The examples are drawn from the first author's work with a class of 16-17 year old students is engaged in a Health class in an Australian suburban high school. (These examples are discussed in detail in (Cahill, 2005; 2011; 2015).The students have been learning about reproduction and sexual health and are well-acquainted with the facts about contraception. A particular learning task invited them to explore within a role-play what a couple might say to establish the need for condom use. Using the premise that knowledge is not on its own enough to enable protective behavior in relation to sexual health, and the paradigmatic presumption that bodies are not separate from things and from other bodies - but are produced through their intra-actions (Barad, 2007) - it seemed important to include an embodied and relational exercise such as that offered within a role-play exercise.

The students worked in pairs, and were asked to cast themselves, choosing an age gender and location for their characters, and create a scene in which their a couple discusses the possibility of condom use. As they began play, it was apparent that it was no simple matter for them to translate their knowledge into embodied inter-action. When they played their scenarios back to the class, the conversations are awkward and indirect. The 
characters were uncomfortable and inarticulate, regardless of whether they were working in single-sex or are mixed pairs. Characteristic approaches included hinting and use of euphemisms. For example girls asking Do you have something with you? and boys asking: Do we need to use protection? None of the characters actually use the word 'condom'.

Despite being articulate in talking about contraception in earlier learning tasks, as soon as they were 'inside' the scene, the rules of engagement changed and the students became inarticulate. As the students performed themselves as those who struggle, a form of reiteration took place. The dominant story was re-circulated, dictating the narrative and shaping the players.

A later exercise however worked to re-position the students and have them engage with the discourses that oriented the interaction. In this activity a version of the naturalistic scene was played again, and then observers were asked to become the 'hidden thoughts' of the characters. They were interviewed about what the characters may have been thinking or feeling but not say aloud in the scene. What might she have been thinking or feeling but not saying out aloud? What might she be afraid of? What might she be hoping for? Those playing the Hidden Thoughts of the "Girlfriend" articulated responses that went something like this:

She thinks she shouldn't have to do this - it should be the guy

She is scared he will think she just sleeps around with anyone and that's why she knows so much about condoms

She worries that this will kill the romance

She wished she was on the pill so she never had to talk about this

She is scared what she will do if he says no - will that mean he is only using her?

She is scared if she drops him she won't get another boyfriend.

She just wants to be in love and have a boyfriend because then it will be like she has a good life.

She hopes it can just go all romantic like in the movies where no one has to worry about this stuff

The Hidden Thoughts of the "Boyfriend" are constructed something like this:

He just wants sex to happen

He is trying to be cool and like he knows how to handle everything 
He doesn't want to get with the reality factor - he just wants it all to happen

He thinks it should be the girl to worry about pregnancy because it's not like he will have a disease or anything

He thinks just this one time can't really cause a problem

He wishes someone had explained all how to do this and when you should have this conversation

He is scared he will get all self-conscious if he has to stop and put on a condom

He never used one before so he thinks it might not feel good

He wants to be in charge but he wants her to organise it all so he doesn't feel like he is to blame if it goes wrong

He is scared she might look down on him if he doesn't know the right way to handle this situation

The 'Hidden Thoughts' questions permit the students to create an awareness of the way in which the characters are shaped by gendered scripts about who, and how to be, and by the sorts of storylines of romance and glamour that are absorbed from the media. The accumulated poly-vocal responses demonstrated that the characters were caught in a set of internalized standards and storylines.

The pedagogical turn accomplished through use of the 'Hidden Thoughts' convention assisted the students to articulate the complexity of underpinning discourses governing the first-told version of the tale. As they embodied and articulated the 'hidden', the underpinning thought-lines became real, recognisable and tangible. The 'Hidden Thoughts' exercise re-positioned by inviting them to fashion a poly-vocal rather than a unitary self. The practice of knowing the self via 'The Hidden Thoughts Game' began on the humanist platform of the naturalistic scene, but accomplished a paradigm shift as it led the participants through a poststructuralist portal to a space within which multiplicity and interconnectedness could be recognized and articulated.

Within a typical classroom mindset, it would be presumed that the students are lacking in some skill, knowledge or motivation when they are unable to accomplish a task. This is the general thrust and shape of schooling. It is not so readily presumed that the problem lies not so much in the individual as in the assemblage of ideas and practices that they live within. A more politicizing frame is activated when it becomes evident that this 'failure' is not so much a breakdown in the performance of an individual, 
as a replication of an inherited pattern. The shift therefore is needed in the public, not just in the private space. Via the hidden thoughts exercise it becomes apparent that body and mind inherently interconnected in the one person, and that minded-bodies are also inherently inter-connected to other bodies - those from the past, as well as those present, and those of the present who are nonetheless absent from the scene. It becomes evident that the storylines are gendered and engendering. However, in this case, the gendered individuals are not so much opposing parties -struggling in a battle of the sexes, but rather they are cogs in the same social machine - a machine that manufactures a silencing shame around sex.

\section{Provoking a paradigm shift}

The need for learning tasks which invite a paradigm shift could also be seen later within the same sexuality education unit. At this later stage the students had covered the basic facts about sexually transmitted infections (STI), and they had commenced a focus on medical help-seeking via an activity which aimed to highlight the need for rapid medical attention in the event of a suspected STI. Again a conventional naturalistic role-play was used. In this case a student volunteered to play the part of an adult aged 22, attending the health clinic to request a sexual health screening. The character was to be motivated by symptoms of painful discharge following a history of unprotected sex with multiple partners.

When the students commenced the scene showing the patient's entry to the consultation room, it became quickly evident that they had created an inarticulate and shame-ridden patient who struggled to speak with a patronizing doctor. There was nothing 'empowering' about this scene, and arguably it would accomplish little in the way of normalizing help-seeking. This because the hidden coda was that the shame-ridden patient deserved their suffering for they had brought their problem upon themselves. A subsequent exercise however produced a very different coda about help-seeking.

In a following exercise the pair was asked to re-cast themselves from doctor-patient to body organs (in which they would play in a surrealist tradition - as they may have met in cartoons or animations.) As body organs, one would play the Penis-with-painful-symptoms and the other player is to be the Brain-with-multiple-demands. Both organs were to be imagined as existing within the same Body. Penis, the site of suffering, cannot take itself to the doctor. But rather must be carried there by the combined effort of other organs. Penis has the task of seeking Brain's assistance with getting 
the Body to the clinic for medical attention in the hope of securing relief from the painful symptoms.

The re-framing of the scene invited a completely different sort of play. In high burlesque, Penis expressed pain, and bewailed Brain's choice to leave Penis unprotected in risky situations. He pleaded to be taken to the doctor to get relief from the pain. Brain defended himself, citing the multiple pressures involved in negotiating life and relationships. The dependent Penis vehemently argued the breach of rights, pointing to his dependence on Brain to advocate for access to healthcare. In watching this the audience was also re-positioned, sympathising with the organ in urgent need of relief from pain, and hoping that the Brain would agree to seek help. In this the embodied intra-action produced a different set of possibilities around help-seeking.

In the new scene, the coda was inverted. It became a story about claiming a right, rather than one about confessing a wrong. It became a politicised rather than a personalised story. This perhaps because one is understood to occupy a position of strength, righteousness or entitlement when making a claim, and a position of weakness, with a desire for self-erasure when confessing.

As via the Hidden Thoughts device, the script that is created exposed the invisible circumstances that were at effect in this scenario - the storylines and discourses, the practices and routines through which people 'learn' what is possible within their world. Whilst the Hidden Thoughts worked to unpeel this backgrounded knowledge by exploring the internal landscape of the individuals, the anthropomorphic activity positioned players to identify patterns and to make claims about how things should be.

\section{Shifting Genre}

In both the early childhood and the teenage examples, the pedagogical process has drawn on shifts in genre to prompt engagement in thought. In the early childhood example there was a shift from consultation about a problem held within a narrative to a fantastical engagement within freeform play. In the problem-centric response the children replicated gender rules. However, in the free form play, they 'bent' the gender rules. In the high school example there were shifts from the narrow re-enactment within the naturalistic play, and more complex and contradictory expositions within the non-naturalistic play. Richardson and St. Pierre (2005) highlight the way in which making a shift in genre in research writing can produce 
a shift in the knowledge that can be constructed. These examples of classroom practice also demonstrate what can be accomplished in the production of knowledge via a shift in genre. In both cases a shift from naturalism to surrealism provided a space within which to access and construct different knowledge. Genre shifts are powerful because they re-frame the rules of reality within which a story can take place. They permit a paradigmatic shift in thinking. It is the paradigm shift that is important for it permits recognition of matter that is commonly left invisible because excluded from the frame of our attention. Taking direction from Barad, a diffractive approach re-locates students' attention, directing thought in lateral rather than just linear directions. The conventional narrative carries a through-line of cause and effect. However, a diffractive approach presumes a rhizomatic progression, through which change is effected and affects through multi-directional movement.

\section{Conclusion}

The examples in this paper have demonstrated that the method of engagement has a function in producing the knowledge that is created in the exchange.

New materialist perspectives highlight that educators need to attend material and affective as well as the discursive to explore the fluid and relational nature of experience and social life. This requires attention to the way in which both question and medium operate to frame that which will be given attention and to shield the matter which will drop from view.

Pedagogical strategies which invite children to engage in a paradigm shift can be usefully harnessed to reveal or disrupt the dominant knowledge presumed within the 'normal science' model through which their worlds are understood. Embodied, diffractive methods can assist to make complexity more visible, and to allow participants to see fluidity, shifts, and becoming. Inside the world of embodied fantasy the players are freed to reveal or construct explanatory stories, and are aided in dealing with the abstract via the embodied nature of their play. The Dolls are objects that lend a real presence to the imagined other. Playing with the dolls however, is different from talking about them. When the children play inside their embodied fantasy they are able to call upon a more complex repertoire of possibility. They are able to embody their thinking showing it through acts and well as through cited opinions. They show patterns by enacting them. In the Hidden Thoughts and Anthropomorphic surrealist play, the young people can shift 
their frame of reference, and begin to look at the dynamic intra-connections between people, ideas, practices and the material world.

Engagement in embodied dramatic play can help to foster the recognition that interactions occur between people - with multi-directional flows of cause and effect taking place between past and present, between objects and persons, between persons and persons, and between discourses and material objects.

As has been illustrated here, pedagogies for engagement which are informed by post-humanist thinking, can engineer the re-framing which prompts recognition of the 'rules of engagement' and which assist players to realize that these rules are constructions, rather than natural laws. As constructions, they are available for re-construction. Dramatic play has been harnessed here, not for its traditional merits in which it is supposed to mirror the 'reality' of the world, but rather for its capacity to illustrate the constructed and enacted nature of life. What is of import here is not the 'mirror', but the recognition that all the world's a stage, with players in an ongoing business of fashioning and being fashioned by movement and meaning-making.

Khun argues that "scientific revolutions are inaugurated by a growing sense... that an existing paradigm has ceased to function adequately in the exploration of an aspect of nature to which that paradigm itself had previously led the way. In both political and scientific development the sense of malfunction that can lead to crisis is prerequisite to revolution" (Kuhn, 1970, p. 92). In Kuhn's model it is the unsettling of the 'normal science' model that prepares the way for a paradigmatic shift in approach to generating new knowledge (Kuhn, 1970). If this model is applied to pedagogical practice, then it can be argued that learning activities which prompt recognition of the unsatisfactory nature of the explanatory model (is this really the way girls and boys are?) and which unsettle students' acceptance of the 'given' (What is holding this in place? Can it be changed?), can prepare the way for a re-thinking of the model (We can imagine a possible world in which we can speak and act free of that constraint!). Building on Butler's (2004) argument, it is the generation of possibility, or the co-creation of new meanings, that lies at the heart of social change. But the unsettling must come first - the deconstruction and interrogation of the given makes space for the emergence of something new.

Building on this argument, it is important that a pedagogy for social change resists the 'normal science' model, which presumes that educators 
must foster a change in the knowledge, skills and attitudes of the individual to 'empower' them to change their behaviour. From the paradigm which permits a feminist material diffractive conceptualization of intra-action, an individual will be better enabled in the matter of self-care and social justice if they are able to see the way the meaning-making machinery of life works to produce patterned interactions, and to frame certain standards and practices as norms. They will be better equipped if prompted to recognize and engage with the ways in which the materials, discourses, and the environments they inhabit work to influence their hopes, fears, beliefs and actions.

Models of interconnectedness are increasingly becoming part of everyday life. Cyber connections are experienced as multitudinous and multidirectional. Knowledge is no longer just something that is meted out by the learned in a linear and programmatic fashion; rather it can be pursued through a web of unpredictable but nonetheless connective pathways. Ecological understandings are expanding as people learn more about the complex interchange of cause and effect mapped in environmental sciences. It is not such a big leap of imagination then, to expect that students will be able to engage with a paradigm of thought which holds that we live in a world in which everything is intra-connected, in which causes are effects, in which reality is re-fashioned as it is lived and witnessed.

\section{References}

Alaimo, S., \& Hekman, S. (2008). Introduction: Emerging models of materiality in feminist theory. In S. Alaimo, \& S. Hekman (Eds.), Material feminisms (pp. 1-19). Bloomington \& Indianapolis: Indiana University Press.

Barad, K. (2007). Meeting the universe halfway: Quantum physics and the entanglement of matter and meaning. Durham \& London: Duke University Press.

Braidotti, R. (2013). The posthuman: John Wiley \& Sons.

Butler, J. (2004). Undoing gender. New York: Routledge.

Cahill, H. (2005). Profound learning: Drama partnerships between adolescents and tertiary students. Drama Australia Journal (NJ), 29 (2), 59-72.

Cahill, H. (2011). Drama for deconstruction. Youth Theatre Journal, 25 (1), 16-31.

Cahill, H. (2015). Rethinking role-play for health and wellbeing: Creating a pedagogy of possibilty. In K. Wright, \& J. McLeod (Eds.), Rethinking youth wellbeing: Critical perspectives (pp. 127-142). Singapore: Springer.

Coleman, R. (2013). Sociology and the virtual: Interactive mirrors, representational thinking and intensive power. The Sociological Review, 61(1), 1-20.

Davis, B. (2003). Frogs and snails and feminist tales. Cresskill, USA: Hampton Press, Inc.

Edwards, R., \& Fenwick, T. (2014). Critique and politics: A sociomaterialist intervention. Educational Philosophy and Theory (ahead-of-print), 1-20. 
Fox, N. J., \& Alldred, P. (2014). The research-assemblage: A new materialist approach to social inquiry. Paper presented at the BSA Annual Conference, Leeds.

Hickey-Moody, A. (2015). Beside ourselves: Worlds beyond people. British Journal of Sociology of Education, 36(5), 802-813.

Kuhn, T. (1970). The Structure of scientific revolutions. Chicago: University of Chicago Press.

Richardson, L., \& St. Pierre, E. A. (2005). Writing: A method of enquiry. In N. Denzin, $\&$ Y. Lincoln (Eds.), The sage handbook of qualitative research (pp. 959-978). Thousand Oaks: Sage.

Ringrose, J., \& Renold, E. (2014). "F**k Rape!": Exploring affective intensities in a feminist research assemblage. Qualitative Inquiry, 20(6), 772-780.

Smith, K., Alexander, K., \& D'Souza Juma, A. (2014). Gender matters in the early childhood classroom. In K. Cologon (Ed.), A Good start: Inclusion in the early years. (pp. 134-151). Oxford: Oxford University Press.

Smith, K. (2013). Diversity dolls as a methodology tool for researching with children about issues of equity. International Journal of Equity and Innovation in Early Childhood. 11(1), 86-96.

Taylor, A. (2013). Reconfiguring the natures of childhood. Milton Park: Routledge.

Taylor, C. A., \& Ivinson, G. (2013). Material feminisms: New directions for education. Gender and Education, 25(6), 665-670.

\section{Authors:}

Helen Cahill, Associate Professor

University of Melbourne

Melbourne Graduate School of Education

Youth Research Centre

Australia

Email: h.cahill@unimelb.edu.au

Julia Coffey, Ph.D.

University of Newcastle

School of Humanities and Social Sciences

Australia

Email: julia.coffey@newcastle.edu.au

Kylie Smith, Ph.D.

University of Melbourne

Melbourne Graduate School of Education

Australia

Email: kylieas@unimelb.edu.au 